\title{
Transient polycythemia during diabetic ketoacidosis triggered by dengue fever in a middle-aged woman
}

\author{
Wattana Insiripong ${ }^{1}$, Somchai Insiripong*2 \\ ${ }^{1}$ Nopparat Rajathanee Hospital, Bangkok, Thailand \\ ${ }^{2}$ Saint Mary Hospital, Nakhon Ratchasima, Thailand
}

Received: December 17, 2019

Accepted: March 30, 2020

Online Published: April 19, 2020

DOI: $10.5430 /$ dcc.v6n3p1

URL: https://doi.org/10.5430/dcc.v6n3p1

\begin{abstract}
Either dengue fever or diabetic ketoacidosis can cause the high hemoglobin concentration due to intravascular volume loss. When both entities were found together as in our case, the hemoglobin concentration could access the strikingly high level until either of them could not contribute it. She was a Thai woman with 46 years of age presenting with fever, fatigue and severe sore throat for a few days. The physical examination showed she had mild dyspnea and oral thrush, the temperature was 36.4 degree Celsius, and her pulse rate was $102 / \mathrm{min}$. Her blood tests showed: $\mathrm{Hb} 18.3 \mathrm{~g} \%$, WBC $9,850 / \mathrm{mm}^{3}$, atypical lymphocyte $10 \%$, platelet 16,000/ $\mathrm{mm}^{3}, \mathrm{MCV} 89.2 \mathrm{fl}$, Dengue NS1 antigen-positive, dengue IgG-positive, IgM-weakly positive, KOH preparation of curd from buccal mucosa-positive for budding yeasts and pseudo-hyphae, blood sugar $442 \mathrm{mg} \%$, triglyceride $578 \mathrm{mg} \%$, Na $122.8 \mathrm{mEq} / \mathrm{L}, \mathrm{K} 6.28 \mathrm{mEq} / \mathrm{L}, \mathrm{Cl} 90.6 \mathrm{mEq} / \mathrm{L}, \mathrm{CO}_{2} 9.2 \mathrm{mEq} / \mathrm{L}$, blood ketone $53.6 \mathrm{mmol} / \mathrm{L}$, lactate $4.5 \mathrm{mmol} / \mathrm{L}, \mathrm{pH} 7.257, \mathrm{pCO}_{2}$ $27.4 \mathrm{mmHg}, \mathrm{HCO}_{3} 11.9 \mathrm{mmo} / \mathrm{L}$, BUN $22.9 \mathrm{mg} \%$, creatinine $0.64 \mathrm{mg} \%$, AST $375 \mathrm{U} / \mathrm{L}$, ALT $224 \mathrm{U} / \mathrm{L}$, alkaline phosphatase $151 \mathrm{U} / \mathrm{L}$. She was diagnosed as having diabetes with diabetic ketoacidosis, dengue fever and polycythemia. She was immediately treated with intravenous fluid therapy to correct the metabolic acidosis, electrolyte imbalance and dehydration, insulin for hyperglycemia, clotrimazole for oral thrush and platelet transfusion. Her high hemoglobin level was dramatically lowered until became normal within one day of therapy whereas she also recovered from DKA although the platelet was progressively lowered every day. It suggested that transient polycythemia was solely contributed by DKA that was triggered by dengue fever hence DKA from dengue fever should be added in the list of unusual causes of transient polycythemia.
\end{abstract}

Key Words: Polycythemia, Dengue fever, Diabetic ketoacidosis

\section{INTRODUCTION}

Dengue fever is a mosquito-borne disease mainly caused by dengue virus. It is clinically characterized by acute febrile illness with nonspecific symptoms such as myalgia and headache. In severe cases, the patients may have low platelet count with or without bleeding symptom, low white blood cell count, pleural effusion, ascites and hemoconcentration due to vascular leakage and subsequently intravascular volume contraction. Few patients may suffer from hypotension, shock or even death. Hemoconcentration that is defined by the $20 \%$ increase of hematocrit ${ }^{[1]}$ can be found in $7 \%$ of cases. In general, the hematocrit in dengue fever could be found ranging from $29.7 \%$ to $48.0 \%$ for adult female patients and from $26.6 \%$ to $59.6 \%$ for adult male patients. ${ }^{[2]}$

Diabetic ketoacidosis (DKA) is acute complication among diabetic patients mainly due to insulin insufficiency. The pa-

\footnotetext{
*Correspondence: Somchai Insiripong; Email: chaikorat@gmail.com; Address: Saint Mary Hospital, Mittrapab Road, Nakhon Ratchasima 30000, Thailand.
} 
tients will suffer from metabolic acidosis, ketone body, hyperkalemia despite total body potassium deficit, hyperglycemia leading to glycosuria and polyuria and subsequently severe dehydration or volume contraction, around 6 lit. $^{[3]}$ By hyperglycemia, the hematocrit can be raised up to $47 \%{ }^{[4]}$ whereas dehydration can raise hematocrit from $42.7 \pm 0.5 \%$ to $44.7 \pm 0.5 \%$. ${ }^{[5]}$

In this report, dengue fever and diabetic ketoacidosis were co-incidentally recognized in a middle-aged woman and they both could lead to the strikingly high level of hemoglobin concentration of which either of them could not contribute it

\section{Case presentation}

A 46-year-old Thai woman presented with fever, malaise, fatigue and sore throat for a few days. The sore throat was so severe hence she could not eat enough food. The physical examination revealed obese woman with oral thrush, dyspnea, and no hepatosplenomegaly. Her vital signs included BW $73.2 \mathrm{~kg}$, BMI $30.4 \mathrm{~kg} / \mathrm{m}^{2}$, temperature 36.4 degree Celsius, BP 122/86 mmHg, P 102/min, RR 22/min, oxygen saturation $100 \%$.

The initial blood tests included: Hb $18.3 \mathrm{~g} \%$, Hct $53.8 \%$, WBC $9,850 / \mathrm{mm}^{3}$, N 52.0\%, L 28.0\%, M 10.0\%, atypical lymphocyte $10 \%$, platelet $16,000 / \mathrm{mm}^{3}$, MCV $89.2 \mathrm{fl}, \mathrm{MCH}$ 30.3 pg, MCHC 34.0 g\%, RDW 12.6\%, Dengue NS1 antigenpositive, dengue IgG-positive, dengue IgM-weakly positive, $\mathrm{KOH}$ preparation of curd from buccal mucosa of left cheekyeasts, budding yeasts and pseudohyphae moderately seen, HBsAg, anti-HCV and HIV Ag/Ab-negative, coagulogramnormal, Blood sugar $442 \mathrm{mg} \%$, Hb A1c 15.4\%, cholesterol $200 \mathrm{mg} \%$, triglyceride $578 \mathrm{mg} \%$, HDL $27 \mathrm{mg} \%$, LDL $140 \mathrm{mg} \%, \mathrm{Na} 122.8 \mathrm{mEq} / \mathrm{L}, \mathrm{K} 6.28 \mathrm{mEq} / \mathrm{L}, \mathrm{Cl} 90.6 \mathrm{mEq} / \mathrm{L}$, $\mathrm{CO} 29.2 \mathrm{mEq} / \mathrm{L}$, ionized Ca $1.12 \mathrm{mmol} / \mathrm{L}$ (normal 1.12-1.32), P $3.8 \mathrm{mg} \%$, BUN $22.9 \mathrm{mg} \%$, creatinine $0.64 \mathrm{mg} \%$, eGFR $107.36 \mathrm{ml} / \mathrm{min} / 1.73 \mathrm{~m}^{2}$, albumin $3.4 \mathrm{~g} \%$, globulin $3.7 \mathrm{~g} \%$, AST $375 \mathrm{U} / \mathrm{L}$, ALT $224 \mathrm{U} / \mathrm{L}$, alkaline phosphatase 151 U/L (normal 30-120), direct bilirubin $0.1 \mathrm{mg} \%$, indirect bilirubin $0.3 \mathrm{mg} \%$, blood ketone $53.6 \mathrm{mmol} / \mathrm{L}$ (normal $<0.6 \mathrm{mmol} / \mathrm{L}$ ), blood lactate $4.5 \mathrm{mmol} / \mathrm{L}$ (normal $<2 \mathrm{mmol} / \mathrm{L}$ ).

The venous blood gas analysis showed $\mathrm{pH}$ 7.257, $\mathrm{pCO}_{2}$ $27.4 \mathrm{mmHg}, \mathrm{pO}_{2} 33.1 \mathrm{mmHg}, \mathrm{BE}-12.8 \mathrm{mmol} / \mathrm{L}, \mathrm{tCO}_{2}$ 12.7, $\mathrm{HCO}_{3} 11.9 \mathrm{mmo} / \mathrm{L}, \mathrm{sO}_{2} 62.1 \%$.

She was diagnosed as having diabetes with diabetic ketoacidosis, dengue fever and polycythemia. She was immediately treated with aggressive intravenous fluid therapy to correct the metabolic acidosis, electrolyte imbalance and dehydration, insulin infusion 4 units an hour for hyperglycemia, clotrimazole lozenge for oral thrush and platelet transfusion. Within 24 hours of intensive care, her blood showed $\mathrm{Hb}$
$14.7 \mathrm{~g} \%$, Hct $43.5 \%$, WBC $11,000 / \mathrm{mm}^{3}$, platelet $12,000 / \mathrm{mm}^{3}$, BS $178 \mathrm{mg} \%$, normal $\mathrm{pH}$ and electrolyte. During 3 days of admission, she never had any bleeding symptom.

The blood tests on the $3^{\text {rd }}$ day of admission: $\mathrm{Hb} 13.4 \mathrm{~g} \%$, Hct $40.5 \%$, WBC $7,000 / \mathrm{mm}^{3}$, platelet $56,000 / \mathrm{mm}^{3}$, AST $156 \mathrm{U} / \mathrm{L}$, ALT $107 \mathrm{U} / \mathrm{L}$, alkaline phosphatase $82 \mathrm{U} / \mathrm{L}$, albumin $2.4 \mathrm{~g} \%$, globulin $2.8 \mathrm{~g} \%$, BUN $5.8 \mathrm{mg} \%$, creatinine $0.44 \mathrm{mg} \%$.

\section{DisCUSSION}

The random blood sugar in our case was more than $200 \mathrm{mg} / \mathrm{dl}$ which was diagnostic for diabetes. ${ }^{[6]}$ The diagnosis of DKA was based on the fulfillment of the biochemical triad of hyperglycemia, ketonemia and high anion gap metabolic acidosis. ${ }^{[7]}$ It can appear as the first presentation of diabetes even in type $2 .^{[8]}$

Besides the inadequate insulin therapy, the common precipitating factor of DKA is the infection. Others include myocardial infarction, cerebrovascular accident, pulmonary embolism, pancreatitis and drugs. ${ }^{[7]}$ The type of infections was found to be pneumonia, the most common, $40.9 \%$, the urinary tract infection $27.3 \%$, tuberculosis $9.1 \%$, diabetic foot $9.1 \%$, gastrointestinal tract infection $4.5 \%$, and mixed infection $9.1 \% .{ }^{[9]}$ Dengue infection is considered the very rare precipitating factor of DKA even in an endemic area for dengue infection like Thailand. ${ }^{[10]}$

The dengue fever was diagnosed in our case based on the clinical syndrome of acute febrile illness, hemoconcentration, thrombocytopenia and confirmed by positive dengue non-structure antigen, and dengue IgM. ${ }^{[11]}$ And dengue fever was presumed to be the trigger of DKA in our case because she had high serum lactate, one significant feature of DKA that is triggered by the infection. ${ }^{[12]}$

An essential criterion of polycythemia vera (PV) is the hemoglobin level $>16.5 \mathrm{~g} \%$ or hematocrit $>49.5 \%$ for female patients. ${ }^{[13]}$ Although the hemoglobin or hematocrit in our case could reach this criterion, the investigation for establishing PV was not promptly performed and it finally resolved in 24 hours of aggressive fluid therapy. If the duration of high blood concentration in the criterion for PV was specified, the attending physician who faced patients with high blood concentration would have confidence to wait for a day or more instead of promptly but wastefully investigating false polycythemia that was found in this situation.

\section{Conclusion}

A 46-year-old Thai woman was admitted because of diabetic ketoacidosis and dengue fever. Although she had strikingly

ISSN 2375-8449 E-ISSN 2375-8473 
high blood concentration, $\mathrm{Hb} 18.3 \mathrm{~g} \%$ or Hct $53.8 \%$, fulfilling the criterion of polycythemia vera, it became normal within one day of fluid therapy. If the duration of high blood concentration was added to hemoglobin or hematocrit criterion of $\mathrm{PV}$, an attending physician would have confidence to wait for a day or more hence unnecessary investigation in false polycythemia could be avoided.

\section{CONFlicts OF Interest Disclosure}

The authors declare they have no conflicts of interest.

\section{REFERENCES}

[1] Srikiatkhachorn A. Plasma leakage in dengue hemorrhagic fever. Thromb Haemost. 2009; 102(6): 1042-1049. PMid:19967133. http $\mathrm{s}: / /$ doi.org/10.1160/TH09-03-0208

[2] Joshi AA, Divyashree BN, Gayathri BR. The hematocrit spectrum in dengue: A prospective study. Int J Sci Stud. 2018; 5(10): 33-37.

[3] Wallace TM, Matthews DR. Recent advances in the monitoring and management of diabetic ketoacidosis. QJM Int J Med. 2004; 97(12): 773-780. PMid:15569808. https://doi.org/10.1093/qjmed/ hch 132

[4] Strauchen JA, Alston W, Anderson J, et al. Inaccuracy in automated measurement of hematocrit and corpuscular indices in the presence of severe hyperglycemia. Blood. 1981; 57(6): 10651067. PMid:6784789. https://doi.org/10.1182/blood.v57. 6.1065 .1065

[5] Ashraf M, Rea R. Effect of dehydration on blood tests. Pract Diabetes. 2017; 34(5): 169-171. https://doi.org/10.1002/pdi.2111

[6] American Diabetes Association. Classification and diagnosis of diabetes: Standards of medical care in diabetes-2019. Diabetes Care. 2019; 42(Supplement 1): S13-S28. PMid:30559228. https : //doi.org/10.2337/dc19-S002

[7] Gosmanov AR, Gosmanova EO, Kitabchi AE. Hyperglycemic crisis: diabetic ketoacidosis (DKA), and hyperglycemic hyperosmolar state (HHS). In: Feingold KR, Anawalt B, Boyce A, et al., editors. Endotext [Internet]. South Dartmouth (MA): MDtext.com, Inc., 2000.
[8] Sharma V, Jobanputra YB, Lewin K, et al. Diabetic ketoacidosis in patients with type 2 diabetes on sodium-glucose cotransporter2 inhibitors. Rev Recent Clin Trials. 2018; 13(2): 156-160. PMid:29542418. https://doi.org/10.2174/15748871136661 80314101436

[9] Seth P, Kaur H, Kaur M. Clinical profile of diabetic ketoacidosis: a prospective study in a tertiary care hospital. J Clin Diagn Res. 2015; 9(6): OC01-OC04. PMid:26266145. https://doi.org/10.786 0/JCDR/2015/8586.5995

[10] Lertdetkajorn K, Sriphrapradang C. Management of diabetic ketoacidosis with dengue hemorrhagic fever. Cureus. 2018; 10(9): e3336. PMid:30473969. https://doi.org/10.7759/cureus. 3336

[11] Kao CL, King CC, Chao DY, et al. Laboratory diagnosis of dengue virus infection: current and future perspectives in clinical diagnosis and public health. J Microbiol Immunol Infect. 2005; 38(1): 5-16.

[12] Azoulay E, Chevret S, Didier J, et al. Infection as a trigger of diabetic ketoacidosis in intensive care-unit patients. Clin Infect Dis 2001; 32(1): 30-35. PMid:11106316. https://doi .org/10. 108 $6 / 317554$

[13] Tefferi A, Barbui T. Polycythemia vera and essential thrombocythemia: 2019 update on diagnosis, risk-stratification and management. Am J Hematol. 2019; 94(1): 133-143. PMid:30281843. https://doi.org/10.1002/ajh.25303 